\title{
Health outcomes in COPD smokers using heated tobacco products: a 3-year follow-up
}

\author{
Riccardo Polosa ${ }^{1,2,3,9}$ - Jaymin B. Morjaria ${ }^{4} \cdot$ Umberto Prosperini $^{5} \cdot$ Barbara Busà $^{6} \cdot$ Alfio Pennisi $^{7}$. \\ Gualberto Gussoni $^{8} \cdot$ Sonja Rust ${ }^{3} \cdot$ Marilena Maglia $^{1,2} \cdot$ Pasquale Caponnetto $^{1,2,3}$
}

Received: 12 December 2020 / Accepted: 13 February 2021 / Published online: 23 March 2021

(c) The Author(s) 2021, corrected publication 2022

\begin{abstract}
Given that many patients with chronic obstructive pulmonary disease (COPD) smoke despite their symptoms, it is important to understand the long-term health impact of cigarette substitution with heated tobacco products (HTPs). We monitored health parameters for 3 years in COPD patients who substantially attenuated or ceased cigarette consumption after switching to HTPs. Changes in daily cigarette smoking, annualized disease exacerbations, lung function indices, patient-reported outcomes (CAT scores) and 6-minute walk distance (6MWD) from baseline were measured in COPD patients using HTPs at 12, 24 and 36 months. These were compared to a group of age- and sex-matched COPD patients who continued smoking. Complete data sets were available for 38 patients (19 in each group). Subjects using HTPs had a substantial decrease in annualized COPD exacerbations within the group mean $( \pm$ SD) from $2.1( \pm 0.9)$ at baseline to $1.4( \pm 0.8), 1.2( \pm 0.8)$ and $1.3( \pm 0.8)$ at $12-, 24-$ and 36-month follow-up ( $p<0.05$ for all visits). In addition, substantial and clinically significant improvements in CAT scores and 6MWD were identified at all three time points in the HTP cohort. No significant changes were observed in COPD patients who continued smoking. This study is the first to describe the long-term health effects of HTP use in COPD patients. Consistent improvements in respiratory symptoms, exercise tolerance, quality of life, and rate of disease exacerbations were observed in patients with COPD who abstained from smoking or substantially reduced their cigarette consumption by switching to HTP use.
\end{abstract}

Keywords Smoking cessation $\cdot$ Heated tobacco products $\cdot$ IQOS $\cdot$ Glo $\cdot$ COPD $\cdot$ Tobacco harm reduction

Riccardo Polosa and Jaymin B. Morjaria have contributed equally towards the writing of the manuscript.

Riccardo Polosa

polosa@unict.it

1 Department of Clinical and Experimental Medicine, University of Catania, Catania, Italy

2 Centre for the Prevention and Treatment of Tobacco Addiction (CPCT), Teaching Hospital "Policlinico-V. Emanuele", University of Catania, Catania, Italy

3 Center of Excellence for the Acceleration of Harm Reduction (CoEHAR), Università di Catania, Catania, Italy

4 Department of Respiratory Medicine, Royal Brompton and Harefield Hospital Foundation Trust, Harefield Hospital, Harefield, UK

\section{Introduction}

Chronic obstructive pulmonary disease (COPD) is an umbrella term used to describe distinct obstructive lung conditions including chronic bronchitis and emphysema

5 Hospital "San Vincenzo", Taormina, Italy

6 UOC Farmacia Ospedaliera, Hospital ARNAS Garibaldi, Catania, Italy

7 Department of Respiratory Medicine, Hospital Clinics "Musumeci-Gecas", Catania, Italy

8 Department for Clinical Research "Centro Studi" FADOI (Scientific Society of Internal Medicine), Milan, Italy

9 UOC Medicina Interna e Urgenza, AOU "Policlinico-V. Emanuele-San Marco", Via S. Sofia, 78-Ed. 4, p. 2, Stanza 78, 95100 Catania, Italy 
$[1,2]$. With over 3 million deaths, COPD is the world's fourth leading cause of death at present [3]. Individuals experience the ill effects of this disease for years and die prematurely from it or its cardio-respiratory complications $[4,5]$. Globally, the COPD burden is expected to increase in the coming decades due to continued exposure to COPD risk factors and/or population ageing [6].

It is well known that cigarette smoking is a significant risk factor for COPD [7-9] and abstaining from smoking is the only evidence-based intervention that improves the prognosis for COPD [10, 11].

Although stopping smoking should be a priority for any smokers with COPD, most of them are unable to experience high success rates during their quit attempts [12, 13]. Licensed quitting therapies (i.e. nicotine replacement therapy (NRT), bupropion, and varenicline) have only limited success in terms of a sustained cessation long-term in patients with COPD who smoke [14].

These patients struggle to completely stop nicotine use and may require prolonged treatment and/or sustained nicotine use to achieve longstanding abstinence from smoking.

An alternative pragmatic approach for patients with COPD who are having difficulty stopping smoking is that of substituting conventional cigarettes with combustion-free nicotine delivery alternatives to achieve significant health gains $[15,16]$.

Although not risk free, emerging clinical evidence suggests that, for example, e-cigarettes use in patients with COPD can help patients with COPD abstain from long-term smoking with clinically relevant health gains [17, 18].

More recently, another class of combustion-free products has been introduced for cigarette substitution, which is also gaining popularity and acceptance by consumers worldwide [19-21]. Heated tobacco products (HTP, also known as heat-not-burn), consist of a holder that electronically transfers controlled heat at temperatures which are below $350{ }^{\circ} \mathrm{C}$ (instead of burning tobacco) to tobacco sticks, plugs, or capsules that generate nicotine-containing aerosols. Since these aerosols are produced at much lower temperatures (compared to combustion, which generally starts at temperature above $400{ }^{\circ} \mathrm{C}$ ), they contain less harmful and potentially harmful chemicals than tobacco smoke, and the overall level of chemical exposure has been shown to be significantly lower in exclusive HTP users compared to smokers [22, 23]. Most popular HTPs are commercially known as "IQOS" by Philip Morris International, "glo" by British American Tobacco, and "Ploom TECH" by Japan Tobacco International. In July 2020, the U.S. FDA authorized the marketing of Philip Morris's "IQOS Tobacco Heating System" as modified risk tobacco products (MRTPs), the first tobacco product to be legally commercialized with the claim of reducing consumers' exposure to harmful chemicals when completely switching away from conventional cigarettes [24].

Given that HTPs have been shown to generate substantially less toxic and potentially harmful chemicals than conventional cigarettes, it is hypothesized that when substituting combustible tobacco cigarettes for HTPs, clinically important health improvements can be observed.

Knowledge of the long-term health impacts of HTP use in this patient population is needed to counsel COPD patients who are using or intend to use HTPs. This awareness is very limited and we are unaware of any published research

that has reported the long-term health consequences of the use of HTPs in COPD. This study is the first to assess objective and subjective health parameters in a cohort of COPD patients who have been daily users of HTPs. Findings were assessed over an observation period of 3 years and compared to those obtained from an age- and sex-matched cohort of smokers with COPD.

\section{Methods}

\section{Patient population}

We conducted a review of medical records of COPD patients regularly attending outpatient clinics in four Italian hospitals. The diagnosis of COPD was made in accordance with the criteria set out by the Global Initiative for Chronic Obstructive Lung Disease (GOLD) [25].

Patients with COPD who reported using HTPs on at least two consecutive outpatient visits (no less than 12 months apart) were deemed eligible and included in the study (HTP users cohort). Datasets from age- and sex-matched COPD patients who regularly smoked cigarettes (and were not using HTPs or e-cigarettes) over the same observation period and attending the same clinics were included as a reference group (cigarette smokers cohort). Approval for the study was obtained by the coordinating center's ethics review board and each patient provided written informed consent.

\section{Study design and assessments}

Study design and evaluations were previously described $[26,27]$. For the cohort of HTP users, the baseline visit was considered a clinical visit prior to the first of the two consecutive follow-up visits, when HTPs were not yet used by COPD patients and they were smoking cigarettes. HTP devices have been noted. Prospective data from COPD HTP users and COPD cigarette smokers were collected at $12 \pm 1.5$ (follow-up visit: F/up1) $24 \pm 1.5$ (F/up2) and $36 \pm 2.5$ (F/ up3) months from October 2017 to September 2020 during their annual follow-up visits. 
Clinical, behavioural, and functional parameters were compared between study cohorts and included: (1) respiratory symptoms, (2) smoking status (biochemically confirmed by exhaled breath carbon monoxide- eCO), cigarette consumption per day (cig/day), as well as HTP use, (3) the annual number of severe COPD exacerbations, (4) postbronchodilator lung function parameters (forced expiratory flow in $1 \mathrm{~s}-\mathrm{FEV} 1$; forced vital capacity-FVC; expiratory ratio-FEV1/FVC; (5) patient-reported outcomes (by COPD Assessment Test-CAT scores) and (6) level of exercise tolerance (by 6-minute walking distance-6MWD test). In addition, we also assessed variations in the relative proportion of COPD GOLD stages over the 3-year study period. The study objectives were not known to the hospital staff who carried out data extraction from patients' medical records. Anonymized datasets were analyzed by a statistician who was blinded to the study cohorts.

Severe exacerbations were defined as changes in the patients' respiratory symptoms requiring a course of antibiotics and/or systemic corticosteroids in addition to nebulized bronchodilators via the primary care physician, emergency department attendance, and/or hospital admission.

The CAT is a health status-validated questionnaire used in COPD patients. A 2 unit difference is considered a minimal clinically important difference in patients' symptomatology $[28,29]$.

The 6MWD is an assessment of the general ability of patients to perform daily tasks. Only patients who were physically capable of carrying out the test underwent 6MWD [30].

\section{Smoking and HTP status}

Smoking consumption was recorded at each study visit as the number of cigarettes smoked on the day before the visit. Smoking abstinence was described as a complete selfreported cessation of conventional smoking (not even a puff) since the previous study visit and biochemically verified by an eCO level of $\leq 7 \mathrm{ppm}$. COPD HTP users who completely stopped cigarette smoking were described as quitters (single users), whereas patients who reported using HTP in conjunction with conventional cigarette smoking were defined as dual users.

\section{Data management and statistical analyses}

Patients' demographic and clinical data were noted at each outpatient visit. Patient data were collected and imputed into an electronic spreadsheet before statistical analyses. Of note, the investigators involved in the analyses of the data did not participate in the medical supervision of the participants in the study or in the extraction of data from the medical records.
In the current analyses, patient parameters are presented as means $[ \pm$ standard deviation $(\mathrm{SD})]$ and medians [interquartile range (IQR)] for parametric and non-parametric data, respectively. Differences in baseline data between the two groups were conducted using Student's $t$ test and Mann-Whitney $U$ test for parametric and non-parametric data, respectively. Data from single and dual users were also extracted for secondary analyses. Statistical within-group analyses using the Student's $t$ test and Wilcoxon-signed rank test were conducted for parametric or non-parametric data at the three time points compared to baseline, respectively. Analysis of repeated measures with Bonferroni correction between the two study groups was conducted for repeated parameter measurements over the 3 years. A two-tailed $p$ value of less than 0.05 was considered of statistical significance. The Statistical Package for Social Science (SPSS for Windows, version 20.0, Chicago, IL, USA) was used to conduct all the statistical assessments.

\section{Results}

\section{Patient characteristics}

A total of 44 COPD patients were considered for the study at baseline, but complete datasets were available for analyses from 38 COPD patients ( 31 male, 7 female) by the end of the study. Three COPD patients in the HTP user group discontinued the use of their device during follow-up (two resulting in relapse to cigarette smoking, one stopping the use of tobacco products completely) and were excluded. Datasets from three COPD patients of the control group were not available for analysis (one moved to a different city area, and two transferred to stroke clinics). The baseline demographics, parameters assessed, and COPD GOLD staging are outlined in Table 1. There were no statistical differences between the two study groups for any of the parameters. Most patients had mild-to-severe airflow limitation as per the COPD GOLD guidelines and were managed accordingly with various combinations of inhaled therapies (corticosteroids, $\beta 2$ agonists and long-acting anti-cholinergics, individually or in combination).

\section{Cigarette consumption and HTP use}

In the COPD HTP users, a significant reduction in conventional cigarette use was noted with a mean $( \pm \mathrm{SD})$ cigarettes/ day of $20.5( \pm 3.4)$ at baseline falling to $1.5( \pm 2), 1.2( \pm 1.8)$ and $1.2( \pm 1.8)$ at F/up1, F/up 2, and F/up 3, respectively ( $p<0.001$ for all 3 visits) (Tables 2, 3; Fig. 1). There were no remarkable differences over the course of the study in the number of cigarettes smoked per day in the COPD controls. Among COPD HTP users, 11/19 (57.9\%) completely 
Table 1 Baseline demographics of the subjects on the study

\begin{tabular}{|c|c|c|c|}
\hline & COPD controls & COPD HTP users & $p$ value \\
\hline $\mathrm{Age}^{\mathrm{b}}$ & $64.9( \pm 5.9)$ & $65.3( \pm 6.5)$ & 0.856 \\
\hline Sex & $16 \mathrm{M}, 3 \mathrm{~F}$ & $15 \mathrm{M}, 4 \mathrm{~F}$ & - \\
\hline \multicolumn{4}{|l|}{$\begin{array}{l}\text { COPD GOLD } \\
\text { staging }\end{array}$} \\
\hline Stage 1 & 1 & 2 & \\
\hline Stage 2 & 4 & 4 & \\
\hline Stage 3 & 9 & 9 & \\
\hline Stage 4 & 5 & 4 & \\
\hline Post-BD FEV $1^{\mathrm{a}}(\mathrm{L})$ & $1.46(1.19,1.68)$ & $1.27(0.98,1.78)$ & 0.333 \\
\hline Post-BD FVC ${ }^{\mathrm{a}}(\mathrm{L})$ & $2.36(2.10,2.61)$ & $2.59(2.07,2.70)$ & 0.333 \\
\hline$\%$ FEV1/FVC ${ }^{b}$ & $60.5( \pm 6.8)$ & $57.2( \pm 10.1)$ & 0.252 \\
\hline $\begin{array}{l}\text { Pack years of } \\
\text { smoking }^{\mathrm{b}}\end{array}$ & $51.8( \pm 11.1)$ & $50.1( \pm 9.5)$ & 0.609 \\
\hline Cig/day ${ }^{b}$ & $20.6( \pm 3.7)$ & $20.5( \pm 3.4)$ & 0.964 \\
\hline CAT score ${ }^{a}$ & $19(17.5,24)$ & $20(17,24.5)$ & 0.333 \\
\hline $\begin{array}{l}\text { COPD } \\
\text { exacerbations }^{\mathrm{b}}\end{array}$ & $2.2( \pm 1.2)$ & $2.1( \pm 0.9)$ & 0.873 \\
\hline $6 \mathrm{MWD}^{\mathrm{a}}(\mathrm{m})$ & $250(202.5,361.8)$ & $281(185,344)$ & 1.000 \\
\hline
\end{tabular}

All analyses were considered significant with a $p$ value $<0.05$ in italic

$C O P D$ chronic obstructive pulmonary disease, $H T P$ heated tobacco product, $M$ male, $F$ female, $B D$ bronchodilator, $L$ litre, $F E V I$ forced expiratory volume in $1 \mathrm{~s}, F V C$ forced vital capacity, $C i g$ conventional cigarettes, CAT COPD assessment tool, 6MWD 6-minute walk distance, $m$ metres

${ }^{a}$ Median (interquartile range)

${ }^{\mathrm{b}}$ Mean ( \pm standard deviation)

abstained from smoking conventional cigarettes (exclusive HTP users/single users) at F/up 3 (Table 4). In those continuing to smoke (dual users), there was a considerable decline in daily cigarette consumption, the mean $( \pm S D)$ cigarettes/day at baseline decreasing from $21( \pm 4.6)$ to 3.6 $( \pm 1.1), 3.3( \pm 1.3)$ and to $3.7( \pm 1)$ at F/up1, F/up2 and F/ up3, respectively ( $p<0.001$ for all three visits) (Table 4$)$. Of note, all dual users consistently reduced their daily smoking by at least $70 \%$ of their baseline consumption throughout the whole duration of the study. Overall, there was a marked reduction in daily cigarettes smoked between the two study groups over the 36-month observation period $(p<0.001)$.

At F/up1, all HTP users were on IQOS. Three IQOS users were found to have switched to glo at F/up2. At F/ up3, 17 HTP users were on IQOS and two on glo. No detail on tobacco stick consumption was recorded.

\section{COPD exacerbations}

COPD HTP users had a significant decline in COPD exacerbations; with the mean $( \pm \mathrm{SD})$ annual exacerbation rate decreasing from $2.2( \pm 1.1)$ at baseline to $1.4( \pm 0.8)$ $(p=0.012), 1.2( \pm 0.8)(p=0.002)$ and $1.3( \pm 0.8)(p=0.004)$ at F/up1, F/up2 and F/up3, respectively (Tables 2, 3). No significant changes in the annual COPD exacerbation rates were observed in the control group. There was an overall significant $(p=0.024)$ between group decrease in annual COPD exacerbations over the observation period (Tables 2 , 3; Fig. 2). In the exclusive (single) HTP users, significant reductions in annual COPD exacerbations from baseline were noted at all three F/up visits (Table 4). Of note, a steady decline in annual COPD exacerbations was also observed in dual users with the mean $( \pm S D)$ yearly exacerbation rate of $2.1( \pm 0.6)$ at baseline declining to $1.6( \pm 0.5)(p=0.108)$ at F/up1, 1.1 $( \pm 0.7)(p=0.077)$ at F/up 2 and $1.2( \pm 0.4)$ at $\mathrm{F} /$ up3 $(p=0.021)($ Table 4$)$.

\section{Lung function assessments and COPD staging}

There was no significant post-baseline improvement in postbronchodilator FEV1 and FVC at any of the follow-up visits in the COPD HTP users (Tables 2, 3). Likewise, no significant change in spirometric indices was observed in the control group throughout the study (Tables 2, 3). Overall, there were no significant differences between the two groups in the spirometric assessments (Tables 2, 3).

GOLD COPD staging changes throughout the study are illustrated in Table 4 and Fig. 3. By the end of the study, three COPD patients in the HTP user group down-staged (i.e. improved) from GOLD COPD Stages 4 and 3 to Stages 2 and 1 ; in contrast, COPD GOLD stage classification was relatively stable in patients belonging to the control group throughout the whole duration of the study.

\section{CAT scores and 6MWD test}

Subjective COPD assessment using CAT scores significantly improved in the COPD HTP user group at all three follow-up visits compared to baseline ( $p<0.01$ at all follow-up visits) (Tables 2,3). Both dual and single users experienced significant reductions (improvements) in CAT scores from baseline (Tables 2, 3). In contrast, there were no significant or clinically relevant improvements noted at any of the follow-up visits from baseline in the control group. Over the 3-year study period, we observed an overall significant improvement in CAT scores between COPD HTP users and COPD smokers $(p=0.008)$ (Tables 2, 3; Fig. 4).

Results of 6MWD at all four follow-up visits were available only for 22 patients (11 from each study group). In the HTP user group, the 6MWD significantly improved from baseline at all follow-up visits $(p<0.01)$, whereas no remarkable improvements in 6MWD were observed in the control group (Tables 2, 3); at F/up3, we observed a median increment in 6MWD of $69 \mathrm{~m}(p=0.005)$ in the COPD HTP user group, whereas there was a small but not significant 
Table 2 Comparison of controls and HTP users at baseline, 12-, 24- and 36-month follow-up visits

\begin{tabular}{|c|c|c|c|c|c|c|c|c|}
\hline & Baseline & $\begin{array}{l}\text { 12-month follow- } \\
\text { up }\end{array}$ & $p$ value $^{c}$ & $\begin{array}{l}\text { 24-month follow- } \\
\text { up }\end{array}$ & $p$ value $^{\mathrm{c}}$ & $\begin{array}{l}\text { 36-month } \\
\text { follow-up }\end{array}$ & $p$ value $^{\mathrm{c}}$ & $\begin{array}{l}\text { Overall between } \\
\text { group } p \text { value } \\
\text { from baseline }\end{array}$ \\
\hline \multicolumn{9}{|c|}{ COPD controls $(n=19)$} \\
\hline $\begin{array}{l}\text { Post-BD FEV } 1^{\mathrm{a}} \\
\text { (L) }\end{array}$ & $1.46(1.19,1.68)$ & $1.41(1.17,1.68)$ & 0.614 & $1.36(1.18,1.67)$ & 0.872 & $1.47(1.18,1.62)$ & 0.643 & 0.469 \\
\hline $\begin{array}{l}\text { Post-BD FVC } \\
\text { (L) }\end{array}$ & $2.36(2.1,2.61)$ & $2.27(2.2,2.71)$ & 0.135 & $2.31(2.16,2.81)$ & 0.251 & $2.3(2.08,2.57)$ & 0.149 & 0.385 \\
\hline$\%$ FEV1/FVC ${ }^{b}$ & $60.5( \pm 6.8)$ & $59.4( \pm 6.7)$ & 0.631 & $59.2( \pm 6.8)$ & 0.575 & $60.8( \pm 8.7)$ & 0.594 & 0.239 \\
\hline Cig/day ${ }^{b}$ & $20.6( \pm 3.7)$ & $20.2( \pm 3.8)$ & 0.764 & $19.8( \pm 5.0)$ & 0.657 & $19.6( \pm 4)$ & 0.650 & $<0.001$ \\
\hline CAT score ${ }^{a}$ & $19(17.5,24)$ & $20(18,22)$ & 0.284 & $20(15.5,24.5)$ & 0.520 & $20(18,23)$ & 0.709 & 0.008 \\
\hline $\begin{array}{l}\text { COPD } \\
\text { exacerbations }^{\mathrm{b}}\end{array}$ & $2.2( \pm 1.1)$ & $2.2( \pm 1)$ & 0.878 & $2.1( \pm 1.1)$ & 0.833 & $2.1( \pm 0.9)$ & 0.728 & 0.024 \\
\hline $6 \mathrm{MWD}^{\mathrm{a}, \mathrm{d}}$ & $250(202.5,361.8)$ & $270(210.5,368.8)$ & 0.872 & $\begin{array}{l}263.5(225.5, \\
374.8)\end{array}$ & 0.182 & $270(216,362)$ & 0.155 & 0.001 \\
\hline \multicolumn{9}{|c|}{ COPD HTP users $(n=19)$} \\
\hline $\begin{array}{l}\text { Post-BD FEV } 1^{\mathrm{a}} \\
\text { (L) }\end{array}$ & $1.27(0.98,1.78)$ & $1.33(0.99,1.77)$ & 0.120 & $1.39(1.05,1.72)$ & 0.064 & $1.30(1.02,1.79)$ & 0.257 & \\
\hline $\begin{array}{l}\text { Post-BD FVC } \\
\text { (L) }\end{array}$ & $2.59(2.07,2.7)$ & $2.6(2.07,2.76)$ & 0.277 & $2.57(2.02,2.91)$ & 0.296 & $2.55(2.03,2.93)$ & 0.376 & \\
\hline$\% \mathrm{FEV} 1 / \mathrm{FVC}^{\mathrm{b}}$ & $57.2( \pm 10.1)$ & $57.1( \pm 10.5)$ & 0.980 & $58.1( \pm 10.2)$ & 0.798 & $57.3( \pm 10.3)$ & 0.984 & \\
\hline $\mathrm{Cig} / \mathrm{day}^{\mathrm{b}}$ & $20.5( \pm 3.4)$ & $1.5( \pm 2)$ & $<0.001$ & $1.2( \pm 1.8)$ & $<0.001$ & $1.2( \pm 1.8)$ & $<0.001$ & \\
\hline CAT score ${ }^{a}$ & $20(17,24.5)$ & $16(14.5,20)$ & $<0.001$ & $17(14.5,19)$ & 0.001 & $15(13,21)$ & 0.006 & \\
\hline $\begin{array}{l}\text { COPD } \\
\text { exacerbations }{ }^{b}\end{array}$ & $2.1( \pm 0.9)$ & $1.4( \pm 0.8)$ & 0.012 & $1.2( \pm 0.8)$ & 0.002 & $1.3( \pm 0.8)$ & 0.004 & \\
\hline $6 \mathrm{MWD}^{\mathrm{a}, \mathrm{d}}(\mathrm{m})$ & $281(185,344)$ & $310(219.5,370)$ & 0.004 & $333(224,370)$ & 0.003 & $350(249,396)$ & 0.005 & \\
\hline
\end{tabular}

Significant differences are noted in bold

Bolditalic indicates significant comparison

$C O P D$ chronic obstructive pulmonary disease, $H T P$ heated tobacco product, $n$ number, $B D$ bronchodilator, $L$ litre, $F E V 1$ forced expiratory volume in $1 \mathrm{~s}, F V C$ forced vital capacity, $C i g$ conventional cigarettes, $C A T$ COPD assessment tool, 6MWD 6-minute walk distance, $m$ metres

${ }^{a}$ Median (interquartile range)

${ }^{\mathrm{b}}$ Mean ( \pm standard deviation)

${ }^{\mathrm{c}}$ Within-group $p$ value vs baseline

${ }^{\mathrm{d}} 11$ subjects in the COPD HTP user group and 11 in the COPD control group at all 3 follow-up visits

increase in median 6MWD of $20 \mathrm{~m}(p=0.155)$ in the COPD control group (Tables 2, 3). Overall, there was a significant improvement $(p=0.001)$ in 6MWD noted between the two study groups over the entire follow-up period (Tables 2, 3).

\section{Discussion}

This study is the first to describe the long-term health effects of daily HTP use in COPD patients. Patients with COPD who abstained from smoking or substantially reduced their cigarette consumption by switching to HTP use experienced improvements in several objective and subjective health parameters, which persisted for up to 3 years. These findings with HTPs were not unexpected because avoiding exposure to chemicals generated from the combustion of tobacco cigarettes is known to slow the COPD progression and to improve patients' health [10,31-33]. Moreover, similar findings have been also reported in COPD patients using another class of combustion-free nicotine delivery products (i.e. e-cigarettes) $[18,26,27]$.

Nearly $60 \%$ of COPD patients using HTPs abstained completely from cigarette smoking throughout the duration of the study, whereas those continuing to smoke (dual users) showed a consistent decline in their daily cigarette consumption from the baseline of at least $70 \%$ at all study visits. This remarkable reduction in overall cigarette consumption may be explained by the effective substitution of conventional cigarettes with HTPs in the COPD patients under investigation. By mimicking the experience of tobacco smoking and its related rituals, HTP use may provide adequate compensatory physical and behavioral effects [34, 35], possibly serving as an effective relapse prevention method and, therefore, 
Table 3 Comparison of HTP and conventional cigarette users (dual users) vs HTP exclusive users (single users) at 12-, 24- and 36-month follow-up visits

\begin{tabular}{|c|c|c|c|c|c|c|c|}
\hline $\begin{array}{l}\text { Parameter } \\
\text { COPD HTP users } \\
\text { reducing cig use (dual } \\
\text { users) }\end{array}$ & $\begin{array}{l}\text { Baseline } \\
(n=8)\end{array}$ & $\begin{array}{l}\text { 12-Month follow-up } \\
(n=8)\end{array}$ & $p$ value $^{\mathrm{c}}$ & $\begin{array}{l}\text { 24-Month follow-up } \\
(n=7)\end{array}$ & $p$ value $^{\mathrm{c}}$ & $\begin{array}{l}\text { 36-Month follow-up } \\
(n=6)\end{array}$ & $p$ value $^{\mathrm{c}}$ \\
\hline Sex & $7 \mathrm{M}, 1 \mathrm{~F}$ & $7 \mathrm{M}, 1 \mathrm{~F}$ & & $7 \mathrm{M}$ & & $6 \mathrm{M}$ & \\
\hline $\begin{array}{l}\text { \% Smoking reduction } \\
\text { from baseline }\end{array}$ & - & $82( \pm 5.7) \%$ & - & $83.9( \pm 6.2) \%$ & - & $81.8( \pm 5.9) \%$ & - \\
\hline Post-BD FEV1 ${ }^{\text {a }}(\mathrm{L})$ & $1.27(0.97,1.88)$ & $1.37(0.99,2.01)$ & 0.024 & $1.85(0.99,2.13)$ & 0.063 & $1.53(0.99,1.97)$ & 0.686 \\
\hline Post-BD FVC $^{\mathrm{a}}$ (L) & $2.47(2.03,3.05)$ & $2.58(2.13,3.1)$ & 0.050 & $2.91(2.37,3.12)$ & 0.176 & $2.84(2.35,3.12)$ & 1.000 \\
\hline$\% \mathrm{FEV} / \mathrm{FVC}^{\mathrm{b}}$ & $56.1( \pm 9.1)$ & $55.9( \pm 10.3)$ & 0.980 & $57( \pm 12.1)$ & 0.863 & $53.7( \pm 10.8)$ & 0.873 \\
\hline $\mathrm{Cig} / \mathrm{day}^{\mathrm{b}}$ & $21( \pm 4.6)$ & $3.6( \pm 1.1)$ & $<0.001$ & $3.3( \pm 1.3)$ & $<0.001$ & $3.7( \pm 1)$ & $<0.001$ \\
\hline CAT score ${ }^{a}$ & $23(18.3,26)$ & $20(16,21)$ & 0.018 & $18(13.5,21)$ & 0.027 & $19(13.5,23.8)$ & 0.027 \\
\hline COPD exacerbations ${ }^{\mathrm{b}}$ & $2.1( \pm 0.6)$ & $1.6( \pm 0.5)$ & 0.108 & $1.1( \pm 0.7)$ & 0.077 & $1.2( \pm 0.4)$ & 0.021 \\
\hline $\begin{array}{l}\text { Parameter } \\
\text { COPD HTP users } \\
\text { ceasing cig use (single } \\
\text { users) }\end{array}$ & $\begin{array}{l}\text { Baseline } \\
(n=11)\end{array}$ & $\begin{array}{l}\text { 12-Month follow-up } \\
(n=11)\end{array}$ & $p$ value $^{\mathrm{c}}$ & $\begin{array}{l}\text { 24-Month follow-up } \\
(n=12)\end{array}$ & $p$ value $^{\mathrm{c}}$ & $\begin{array}{l}\text { 36-Month follow-up } \\
(n=13)\end{array}$ & $p$ value $^{\mathrm{c}}$ \\
\hline Sex & $8 \mathrm{M}, 3 \mathrm{~F}$ & $8 \mathrm{M}, 3 \mathrm{~F}$ & & $8 \mathrm{M}, 4 \mathrm{~F}$ & & $9 \mathrm{M}, 4 \mathrm{~F}$ & \\
\hline $\begin{array}{l}\text { \% Smoking reduction } \\
\text { from baseline }\end{array}$ & - & $100 \%$ & - & $100 \%$ & - & $100 \%$ & - \\
\hline Post-BD FEV1ª (L) & $1.38(1.03,1.71)$ & $1.26(1.02,1.75)$ & 0.722 & $1.35(1.17,1.64)$ & 0.504 & $1.3(1.1,1.65)$ & 0.401 \\
\hline Post-BD FVC $^{\mathrm{a}}(\mathrm{L})$ & $2.6(2.19,2.67)$ & $2.6(2.7,2.73)$ & 0.689 & $2.44(1.83,2.83)$ & 0.814 & $2.5(1.8,2.78)$ & 0.727 \\
\hline$\% \mathrm{FEV} / \mathrm{FVC}^{\mathrm{b}}$ & $58.1( \pm 11)$ & $58( \pm 11)$ & 0.991 & $58.7( \pm 9.2)$ & 0.675 & $59( \pm 10)$ & 0.881 \\
\hline $\mathrm{Cig} / \mathrm{day}^{\mathrm{b}}$ & $20.2( \pm 2.3)$ & - & & - & & - & \\
\hline CAT score ${ }^{a}$ & $18(17,23)$ & $15(14,17)$ & 0.004 & $16(14.8,18)$ & 0.003 & $15(14,20)$ & 0.036 \\
\hline COPD Exacerbations ${ }^{b}$ & $2.1( \pm 1)$ & $1.2( \pm 1)$ & 0.048 & $1.3( \pm 0.9)$ & 0.021 & $1.3( \pm 1)$ & 0.035 \\
\hline
\end{tabular}

Significant differences are noted in bold

Bolditalic indicates significant comparison

$C O P D$ chronic obstructive pulmonary disease, $H T P$ heated tobacco product, $n$ number, $B D$ bronchodilator, $L$ litre, $F E V 1$ forced expiratory volume in $1 \mathrm{~s}, F V C$ forced vital capacity, Cig conventional cigarettes, CAT COPD assessment tool, $6 M W D$ 6-minute walk distance, $m$ metres

${ }^{a}$ Median (interquartile range)

${ }^{\mathrm{b}}$ Mean ( \pm standard deviation)

${ }^{\mathrm{c}}$ Within-group $p$ value vs baseline

contributing to the low relapse rates observed in the HTP users of this study.

Holding off from chronic exposure to combustion chemicals is expected to improve several health outcomes in COPD patients, but long-term health consequences of regular HTP use have not been explored. An important finding is that COPD exacerbations were consistently reduced throughout the whole duration of the study by approximately $40 \%$ in patients who stopped or considerably reduced their smoking consumption after switching to HTPs. The proportion of COPD exacerbations prevented in these patients is of clinical significance and similar to that observed with standard medications [36]. Chronic exposure to cigarette smoke enhances susceptibility to infections of the respiratory tract [37] and it has been shown to be a risk factor for bacterial and viral infections
$[38,39]$ as well as for respiratory exacerbations in COPD patients [40]. Given that stopping smoking is associated with a lower risk, switching to HTP use would be expected to result in a marked attenuation of respiratory infections and COPD exacerbations, as shown in this study.

Consistent improvements were also observed in overall health status and physical activity in COPD patients who quit or reduced substantially their cigarette consumption by substitution with HTPs. The improvements in patientreported outcomes (by CAT scores) and level of exercise tolerance (by 6MWD test) in the COPD HTP user group were consistent throughout the whole duration of the study. Of note, significant improvements in CAT scores were observed for both dual users and exclusive HTP users. The observed CAT and 6MWD changes in this study are similar to those reported in COPD patients undergoing intensive 


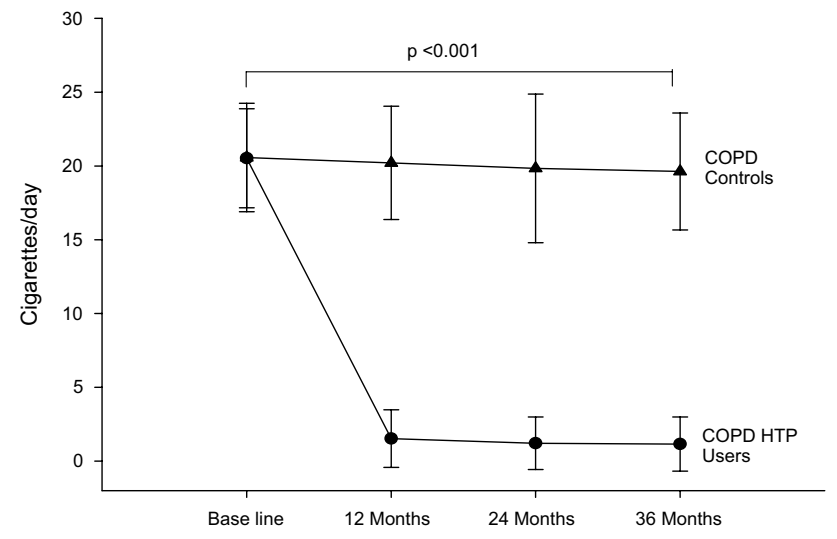

Fig. 1 Number of cigarettes smoked per day at baseline, followup visit 1 (12 \pm 1.5 months), visit $2(24 \pm 2.5$ months) and visit 3 (36 \pm 3 months) in COPD-heated tobacco product users (closed circles) and COPD controls (closed triangles). All data expressed as mean and error bars are standard deviation of the mean. COPD chronic obstructive pulmonary disease, HTP heated tobacco products

rehabilitation programs [29, 41]. These improved health outcomes may be explained by the marked decline in carbon monoxide exposure and in carboxyhaemoglobin levels following cigarette substitution with combustion-free HTPs [42] and the associated time-dependent improvement in exercise tolerance that occurs after quitting smoking [43]. The same explanation may also hold up for dual users given that they greatly reduced their daily smoking consumption by more than $70 \%$.

Given the improvements in exacerbation rates, respiratory symptoms, and overall health status, it was not surprising to note for COPD patients in the HTP user group consistent downstaging (i.e. improvement) of their GOLD COPD stages throughout the whole duration of the study.

No significant post-baseline improvement in spirometric indices was observed in COPD HTP users with the only exception of a trend towards amelioration in FEV1 at 24 months, which-however-was small and well within the variability of the test. The absence of significant

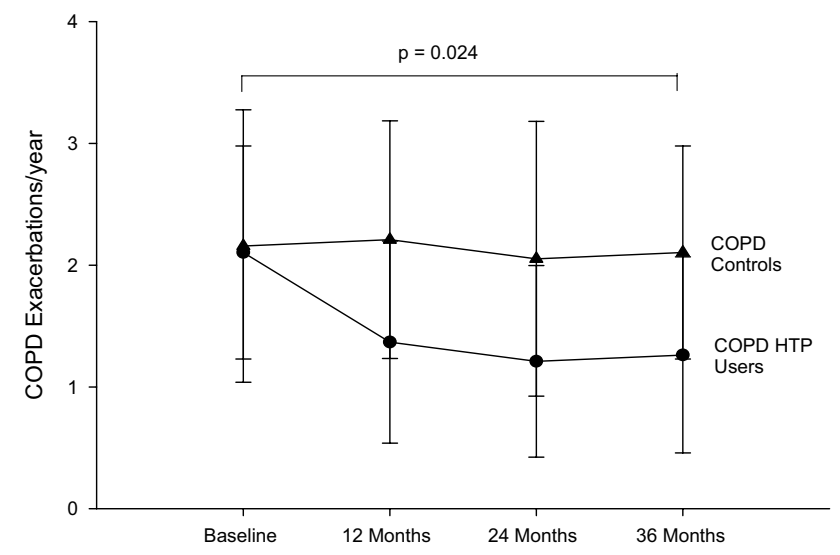

Fig. 2 Number of COPD exacerbations per year at baseline, followup visit $1(12 \pm 1.5$ months), visit $2(24 \pm 2.5$ months $)$ and visit 3 (36 \pm 3 months) in COPD-heated tobacco product users (closed circles) and COPD controls (closed triangles). Data expressed as mean and error bars are standard deviation of the mean. COPD chronic obstructive pulmonary disease, HTP heated tobacco products

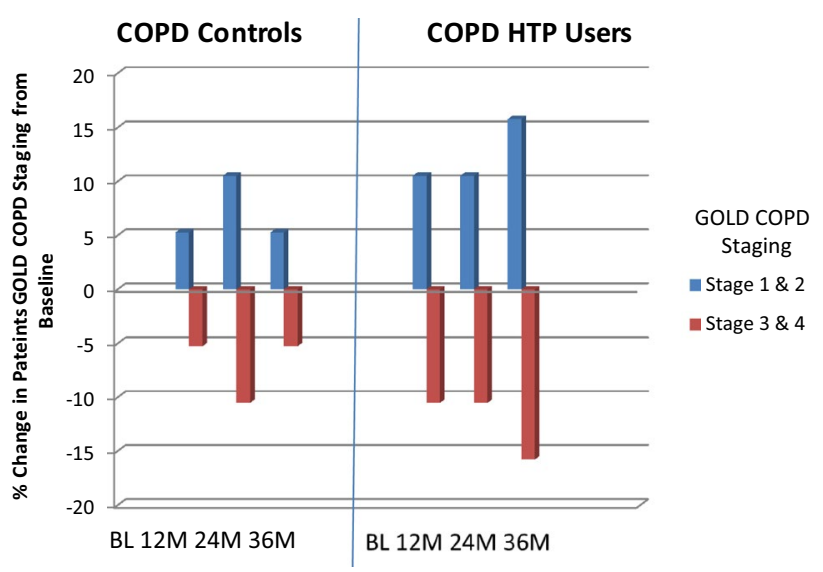

Fig. 3 Percentage change in patients COPD GOLD stage from baseline in COPD-heated tobacco product users and COPD controls. $C O P D$ chronic obstructive pulmonary disease, HTP heated tobacco products, GOLD Global initiative in Obstructive Lung Disease, $B L$ baseline, $M$ months

Table 4 COPD GOLD stage changes over the study period

\begin{tabular}{|c|c|c|c|c|c|c|c|c|}
\hline \multirow{2}{*}{$\begin{array}{l}\text { COPD } \\
\text { GOLD } \\
\text { stage }\end{array}$} & \multicolumn{2}{|l|}{ Baseline } & \multicolumn{2}{|l|}{12 months } & \multicolumn{2}{|l|}{24 months } & \multicolumn{2}{|l|}{36 months } \\
\hline & $\begin{array}{l}\text { COPD controls } \\
n(\%)\end{array}$ & $\begin{array}{l}\text { COPD HTP } \\
\text { users } \\
n(\%)\end{array}$ & $\begin{array}{l}\text { COPD controls } \\
n(\%)\end{array}$ & $\begin{array}{l}\text { COPD HTP } \\
\text { users } \\
n(\%)\end{array}$ & $\begin{array}{l}\text { COPD controls } \\
n(\%)\end{array}$ & $\begin{array}{l}\text { COPD HTP } \\
\text { users } \\
n(\%)\end{array}$ & $\begin{array}{l}\text { COPD controls } \\
n(\%)\end{array}$ & $\begin{array}{l}\text { COPD HTP } \\
\text { users } \\
n(\%)\end{array}$ \\
\hline Stage 1 & $1(5.3 \%)$ & $2(10.5 \%)$ & $2(10.5 \%)$ & $2(10.5 \%)$ & $2(10.5 \%)$ & $2(10.5 \%)$ & $0(0.0 \%)$ & $2(10.5 \%)$ \\
\hline Stage 2 & $4(21.0 \%)$ & $4(21.0 \%)$ & $4(21.0 \%)$ & $6(31.6 \%)$ & $5(26.3 \%)$ & $6(31.6 \%)$ & $6(31.6 \%)$ & $7(36.8 \%)$ \\
\hline Stage 3 & $9(47.4 \%)$ & $9(47.4 \%)$ & $9(47.4 \%)$ & $8(42.1 \%)$ & $8(42.1 \%)$ & $9(47.4 \%)$ & $8(42.1 \%)$ & $7(36.8 \%)$ \\
\hline Stage 4 & $5(26.3 \%)$ & $4(21.0 \%)$ & $4(21.0 \%)$ & $3(15.8 \%)$ & $4(21.0 \%)$ & $2(10.5 \%)$ & $5(26.3 \%)$ & $3(15.8 \%)$ \\
\hline
\end{tabular}

GOLD Global strategy on Obstructive Lung Disease, COPD chronic obstructive pulmonary disease, $n$ subject numbers, HTP heated tobacco products 


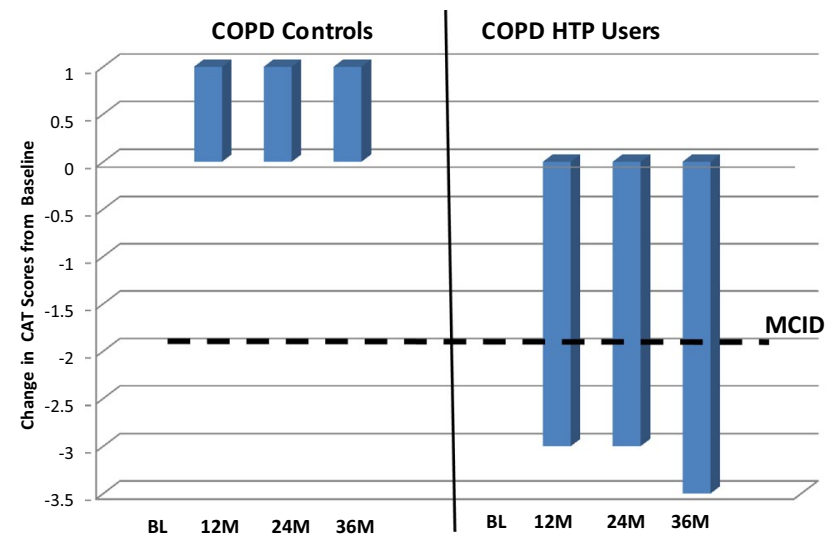

Fig. 4 Change in the median COPD assessment tool (CAT) scores from baseline in COPD-heated tobacco product users and COPD controls. The bold solid line on the bar chart represents the minimal clinically important difference (MCID) for CAT score. A decrease of at least 2 units from baseline is considered to be of clinical importance. $C O P D$ chronic obstructive pulmonary disease, $H T P$ heated tobacco products, $C A T$ COPD Assessment Tool, $B L$ baseline, $M$ months, $M C I D$ minimal clinically important difference

changes in spirometry is not unusual in COPD smokers who stop smoking and particularly in patients with advanced disease and irreversible airway obstruction [44, 45], as is the case in our study population. Nonetheless, no worsening in respiratory physiology (including post-bronchodilator FEV1, FVC, and \%FEV1/FVC) was reported in COPD patients who were using HTPs.

There are a range of drawbacks to our analysis. First, our results are based on a small cohort of patients with COPD and must be interpreted cautiously. Nonetheless, beneficial results were consistently observed in many COPD health metrics over the entire 3-year period of the study. Second, COPD HTP users in this study could represent a self-selected sample; we cannot rule out that only those who experienced respiratory symptom improvement continued to use HTPs and were ultimately selected for the study. Finally, roughly half of the study participants did not undergo the 6MWD test and this limits the statistical strength of our results.

Risk reduction and harm reversal in the form of cigarette substitution with low-risk products appear to be a promising path. Our study in COPD smokers shows that among those who have substituted conventional combustible cigarettes for HTPs, long-lasting improvements in respiratory symptoms, exercise tolerance, quality of life, and the rate of disease exacerbations are possible.

Poor quality of life and unsatisfactory response to medical care remain unmet needs for COPD patients who smoke. Therefore, any measures that can improve their symptoms should not be dismissed light-heartedly. Given that, despite the negative health consequences, many
COPD smokers prefer to smoke, conventional cigarette substitution should be seen as a valuable solution to the challenging problem of smoking, and combustion-free nicotine delivery technologies, such as HTPs, should be seen as part of this strategy.

To verify our preliminary findings on the effectiveness, tolerability and harm reduction potential of these new technologies in COPD, broader prospective studies on the long-term health impacts of heated tobacco products are required. Increasing the knowledge base about the respiratory health risks and benefits of smoking substitution with HTP use is a key for better policy-making and for better quality of information to end-users.

Author contributions $\mathrm{RP}$ - study design, data interpretation, manuscript drafting and revision. JBM-data analyses, data interpretation, manuscript drafting and revision. UP_review of medical records and data collection. $\mathrm{BB}$-review of medical records and data collection. $\mathrm{AP}$ - review of medical records and data collection. GG-data interpretation and manuscript revision. SR - manuscript revision. MMreview of medical records and data collection. PC—study design, data interpretation and manuscript revision. All authors have read and approved the final manuscript.

Funding Open access funding provided by Università degli Studi di Catania within the CRUI-CARE Agreement. This research was supported by University Grant no. 21040100 of "Ricerca Scientifica Finanziata dall'Ateneo di Catania".

\section{Compliance with ethical standards}

Conflict of interest RP is a full-time employee of the University of Catania, Italy, and Medical Director of the Institute for Internal Medicine and Clinical Immunology at the same University. In relation to his work in the area of tobacco control and respiratory diseases, RP has received lecture fees and research funding from Pfizer, GlaxoSmithKline, CV Therapeutics, NeuroSearch A/S, Sandoz, MSD, Boehringer Ingelheim, Novartis, Duska Therapeutics, and Forest Laboratories. He has also served as a consultant for Pfizer, Global Health Alliance for treatment of tobacco dependence, CV Therapeutics, Boehringer Ingelheim, Novartis, Duska Therapeutics, ECITA (Electronic Cigarette Industry Trade Association, in the UK), Arbi Group Srl., and Health Diplomats. RP has served on the Medical and Scientific Advisory Board (MSAB) of Cordex Pharma, Inc., CV Therapeutics, Duska Therapeutics Inc, Pfizer, and PharmaCielo. Lecture fees from a number of European EC industry and trade associations (including FIVAPE in France and FIESEL in Italy) were directly donated to vaper advocacy no-profit organizations. RP is also the founder of (1) the Center for Tobacco Prevention and treatment (CPCT) at the University of Catania and (2) the Center of Excellence for the acceleration of Harm Reduction (CoEHAR) at the same University, which has received support from Foundation for a Smoke-Free World to conduct eight independent investigator-initiated research projects on harm reduction. RP is also currently involved in the following pro bono activities: scientific advisor for LIAF, Lega Italiana Anti Fumo (Italian acronym for Italian AntiSmoking League), the Consumer Advocates for Smoke-free Alternatives (CASAA) and the International Network of Nicotine Consumers Organizations (INNCO); Chair of the European Technical Committee for standardization on "Requirements and test methods for emissions of electronic cigarettes" (CEN/TC 437; WG4). JBM has received hon- 
oraria for speaking and financial support to attend meetings/advisory boards from Wyeth, Chiesi, Pfizer, MSD, Boehringer Ingelheim, Teva, GSK/Allen \& Hanburys, Napp, Almirall, AstraZeneca, Trudell, Cook Medical, Medela AG and Novartis. He has been an expert witness for a solicitor company acting for BATSA and all proceeds of the work were donated to a number of charities. All other authors have no relevant conflict of interest to declare in relation to this study.

Statement on human and animal rights This observational (non interventional) study has been approved by our local ERB. All procedures performed in studies involving human participants were in accordance with the ethical standards of the institutional and/or national research committee and with the 1964 Helsinki declaration and its later amendments or comparable ethical standards.

Informed consent All participants provided informed consent prior to their participation.

Open Access This article is licensed under a Creative Commons Attribution 4.0 International License, which permits use, sharing, adaptation, distribution and reproduction in any medium or format, as long as you give appropriate credit to the original author(s) and the source, provide a link to the Creative Commons licence, and indicate if changes were made. The images or other third party material in this article are included in the article's Creative Commons licence, unless indicated otherwise in a credit line to the material. If material is not included in the article's Creative Commons licence and your intended use is not permitted by statutory regulation or exceeds the permitted use, you will need to obtain permission directly from the copyright holder. To view a copy of this licence, visit http://creativecommons.org/licenses/by/4.0/.

\section{References}

1. Morjaria JB, Malerba M, Polosa R (2010) Biologic and pharmacologic therapies in clinical development for the inflammatory response in COPD. Drug Discov Today 15:396-405

2. Vestbo J, Hurd SS, Agustí AG et al (2013) Global strategy for the diagnosis, management, and prevention of chronic obstructive pulmonary disease: GOLD executive summary. Am J Respir Crit Care Med 187:347-365

3. Lozano R, Naghavi M, Foreman K et al (2012) Global and regional mortality from 235 causes of death for 20 age groups in 1990 and 2010: a systematic analysis for the Global Burden of Disease Study 2010. Lancet 380(9859):2095-2128

4. Falk JA, Kadiev S, Criner GJ et al (2008) Cardiac disease in chronic obstructive pulmonary disease. Proc Am Thorac Soc 5:543-548

5. MacNee W (2005) Pathogenesis of chronic obstructive pulmonary disease. Proc Am Thorac Soc 2:258-266

6. Mathers CD, Loncar D (2006) Projections of global mortality and burden of disease from 2002 to 2030. PLoS Med 3(11):e442

7. U.S. Department of Health and Human Services (1984) The health consequences of smoking: chronic obstructive lung disease. U.S. Department of Health and Human Services, Public Health Service, Office on Smoking and Health, Rockville

8. U.S. Department of Health and Human Services (2004) The health consequences of smoking: a report of the Surgeon General. Department of Health and Human Services, Centers for Disease Control and Prevention, National Center for Chronic Disease Prevention and Health Promotion, Office on Smoking and Health, Atlanta

9. Ezzati M, Lopez AD (2003) Estimates of global mortality attributable to smoking in 2000. Lancet 362:847-852
10. U.S. Department of Health and Human Services (1990) The health benefits of smoking cessation. U.S. Department of Health and Human Services, Public Health Service, Centers for Disease Control, Center for Chronic Disease Prevention and Health Promotion, Office on Smoking and Health. DHHS Publication No. (CDC) 90-8416

11. Hersh CP, DeMeo DL, Al-Ansari E et al (2004) Predictors of survival in severe, early onset COPD. Chest 126:1443-1451

12. Jimenez-Ruiz CA, Masa F, Miravitlles M et al (2001) Smoking characteristics: differences in attitudes and dependence between healthy smokers and smokers with COPD. Chest 119:1365-1370

13. van der Meer RM, Wagena EJ, Ostelo RW et al (2003) Smoking cessation for chronic obstructive pulmonary disease. Cochrane Database Syst Rev. https://doi.org/10.1002/14651858.cd002999

14. Tashkin DP (2015) Smoking cessation in chronic obstructive pulmonary disease. Semin Respir Crit Care Med 36:491-507. https://doi.org/10.1055/s-0035-1555610

15. Polosa R, Rodu B, Caponnetto P, Maglia M, Raciti C (2013) A fresh look at tobacco harm reduction: the case for the electronic cigarette. Harm Reduct J 4(10):19. https://doi.org/10. 1186/1477-7517-10-19

16. O'Leary R, Polosa R (2020) Tobacco harm reduction in the 21st century. Drugs Alcohol Today 20(3):219-234. https://doi.org/ 10.1108/DAT-02-2020-0007

17. Morjaria JB, Mondati E, Polosa R (2017) E-cigarettes in patients with COPD: current perspectives. Int J Chron Obstruct Pulmon Dis 1(12):3203-3210. https://doi.org/10.2147/COPD.S135323

18. Polosa R, Morjaria JB, Prosperini U, Busà B, Pennisi A, Malerba M, Maglia M, Caponnetto P (2020) COPD smokers who switched to e-cigarettes: health outcomes at 5-year follow up. Ther Adv Chronic Dis 10(11):2040622320961617. https:// doi.org/10.1177/2040622320961617

19. Polosa R, Farsalinos K, Prisco D (2019) Health impact of electronic cigarettes and heated tobacco systems. Intern Emerg Med 14(6):817-820. https://doi.org/10.1007/s11739-019-02167-4

20. https://tobaccobusiness.com/philip-morris-international-releases2020-third-quarter-financial-report/. Accessed 4 Jan 2021

21. https://www.bat.com/group/sites/UK_9D9KCY.nsf/vwPagesWeb Live/DOAWWGJT/\$file/BAT_Annual_Report_and_Form_20-F_ 2019.pdf. Accessed 4 Jan 2021

22. Haziza C, de La Bourdonnaye G, Merlet S, Benzimra M, Ancerewicz J, Donelli A, Baker G, Picavet P, Lüdicke F (2016) Assessment of the reduction in levels of exposure to harmful and potentially harmful constituents in Japanese subjects using a novel tobacco heating system compared with conventional cigarettes and smoking abstinence: a randomized controlled study in confinement. Regul Toxicol Pharmacol 81:489-499. https://doi.org/ 10.1016/j.yrtph.2016.09.014

23. Gale N, McEwan M, Camacho OM, Hardie G, Murphy J, Proctor CJ (2020) Changes in biomarkers of exposure on switching from a conventional cigarette to the glo tobacco heating product: a randomized, controlled ambulatory study. Nicotine Tob Res 10:ntaa135. https://doi.org/10.1093/ntr/ntaa135 (Epub ahead of print)

24. https://www.fda.gov/news-events/press-announcements/fda-autho rizes-marketing-iqos-tobacco-heating-system-reduced-exposureinformation. Accessed 4 Jan 2021

25. Global Initiative For Chronic Obstructive Lung Disease (2008) Global strategy for the diagnosis, management, and prevention of chronic obstructive pulmonary disease (updated 2008). http:// goldcopd.org. Accessed 4 Jan 2021

26. Polosa R, Morjaria JB, Caponnetto P, Prosperini U, Russo C, Pennisi A, Bruno CM (2016) Evidence for harm reduction in COPD smokers who switch to electronic cigarettes. Respir Res 17(1):166. https://doi.org/10.1186/s12931-016-0481-x 
27. Polosa R, Morjaria JB, Prosperini U, Russo C, Pennisi A, Puleo R, Caruso M, Caponnetto P (2018) Health effects in COPD smokers who switch to electronic cigarettes: a retrospective-prospective 3-year follow-up. Int J Chron Obstruct Pulmon Dis. 22(13):25332542. https://doi.org/10.2147/COPD.S161138

28. Jones PW, Harding G, Berry P et al (2009) Development and first validation of the COPD assessment test. Eur Respir J 34:648-654

29. Kon SS, Canavan JL, Jones SE et al (2014) Minimum clinically important difference for the COPD assessment test: a prospective analysis. Lancet Respir Med 2:195-203

30. ATS Committee on Proficiency Standards for Clinical Pulmonary Function Laboratories (2002) ATS statement: guidelines for the six-minute walk test. Am J Respir Crit Care Med 166:111-117

31. Anthonisen NR, Connett JE, Kiley JP et al (1994) Effects of smoking intervention and the use of an inhaled anticholinergic bronchodilator on the rate of decline of FEV1. The lung health study. JAMA 272:1497-1505

32. Burchfiel CM, Marcus EB, Curb JD et al (1995) Effects of smoking and smoking cessation on longitudinal decline in pulmonary function. Am J Respir Crit Care Med 151:1778-1785

33. Kanner RE, Connett JE, Williams DE et al (1999) Effects of randomized assignment to a smoking cessation intervention and changes in smoking habits on respiratory symptoms in smokers with early chronic obstructive pulmonary disease: the lung health study. Am J Med 106:410-416

34. Xu SS, Meng G, Yan M, Gravely S, Quah ACK, Ouimet J, O'Connor RJ, Sutanto E, Yoshimi I, Mochizuki Y, Tabuchi T, Fong GT (2020) Reasons for regularly using heated tobacco products among adult current and former smokers in Japan: finding from 2018 ITC Japan Survey. Int J Environ Res Public Health 17(21):8030. https://doi.org/10.3390/ijerph17218030

35. Tompkins CNE, Burnley A, McNeill A, Hitchman SC (2020) Factors that influence smokers' and ex-smokers' use of IQOS: a qualitative study of IQOS users and ex-users in the UK. Tob Control. https://doi.org/10.1136/tobaccocontrol-2019-055306 (Epub ahead of print)

36. Aaron SD (2014) Management and prevention of exacerbations of COPD. BMJ 349:g5237

37. Feldman C, Anderson R (2013) Cigarette smoking and mechanisms of susceptibility to infections of the respiratory tract and other organ systems. J Infect 67:169-184
38. Almirall J, Bolíbar I, Serra-Prat M, Roig J, Hospital I, Carandell E, Agustí M, Ayuso P, Estela A, Torres A, Community-Acquired Pneumonia in Catalan Countries (PACAP) Study Group (2008) New evidence of risk factors for community-acquired pneumonia: a population-based study. Eur Respir J. 31(6):1274-1284. https:// doi.org/10.1183/09031936.00095807

39. Lawrence H, Hunter A, Murray R, Lim WS, McKeever T (2019) Cigarette smoking and the occurrence of influenza-systematic review. J Infect 79(5):401-406. https://doi.org/10.1016/j.jinf. 2019.08.014

40. Au DH, Bryson CL, Chien JW et al (2009) The effects of smoking cessation on the risk of chronic obstructive pulmonary disease exacerbations. J Gen Intern Med 24:457-463

41. Greulich T, Koczulla AR, Nell C et al (2015) Effect of a threeweek inpatient rehabilitation program on 544 consecutive patients with very severe COPD: a retrospective analysis. Respiration 90(4):287-292

42. Caponnetto P, Maglia M, Prosperini G, Busà B, Polosa R (2018) Carbon monoxide levels after inhalation from new generation heated tobacco products. Respir Res 19(1):164. https://doi.org/ 10.1186/s12931-018-0867-z

43. Berkovitch A, Kivity S, Klempfner R et al (2015) Time-dependent relation between smoking cessation and improved exercise tolerance in apparently healthy middle-age men and women. Eur J Prev Cardiol 22:807-814

44. Scanlon PD, Connett JE, Waller LA et al (2000) Smoking cessation and lung function in mild-to-moderate chronic obstructive pulmonary disease. The Lung Health Study. Am J Respir Crit Care Med. 161(2 Pt 1):381-390

45. Tashkin DP, Rennard S, Taylor Hays J, Lawrence D, Marton JP, Lee TC (2011) Lung function and respiratory symptoms in a 1 -year randomized smoking cessation trial of varenicline in COPD patients. Respir Med 105(11):1682-1690

Publisher's Note Springer Nature remains neutral with regard to jurisdictional claims in published maps and institutional affiliations. 